\title{
Etiological Pattern of Movement Disorders in Children
}

\author{
Navya N. Parameshwarappa ${ }^{1} \cdot$ Vykuntaraju K. Gowda $^{2}$ - Sanjay K. Shivappa ${ }^{1}$
}

Received: 24 April 2021 / Accepted: 7 June 2021 / Published online: 25 June 2021

(c) Dr. K C Chaudhuri Foundation 2021

To the Editor:Movement disorders are characterized by impaired voluntary movement, the presence of involuntary movements, or both [1]. Determining the etiology is important for the specific treatment and prognostication. As there are limited Indian studies, we planned this study with the objective of establishing their underlying etiology. This observational study was conducted from January 2018 to June 2019. Children from 2 mo to 18 y of age with involuntary movements were included. History, clinical examination, video graphics of movements, and diagnostic workup were analyzed. The study was approved by the institutional ethics committee.

A total of 104 cases (male:female ratio, 50:50), with mean age of $4.3 \mathrm{y}$ were analyzed. Etiologically, perinatal insult was the most common $-29(28 \%)$, followed by hereditary causes $-26(25 \%)$, infection or immune mediated -8 (8\%), psychogenic or behavioral causes $-8(8 \%)$, and others $-19(18 \%)$ were noted. Among the perinatal insults, hypoxic ischemic encephalopathy (HIE) -19/104 (18.3\%) followed by bilirubin-induced neurological dysfunction (BIND) $-5 / 104(4.8 \%)$ were seen. Rheumatic chorea was noted in $5 / 104(4.9 \%)$ cases. Gratification reaction 5/8 (62.5\%) and shuddering attacks $3 / 8(37.5 \%)$ were noted in the psychogenic/behavioral causes. Of 19 children with others etiology, infantile tremor syndrome was the commonest $(n=16)$.

Earlier literature showed rheumatic chorea as the most common cause of choreaas reported by Goraya 6/19 (31.6\%) [2], but in this study, it accounts for 5 (17.3\%) cases, like Dale et al. 3/20 (15\%) [3]. This may be attributed to better diagnosis and treatment of streptococcal infections and improving living status. ITS accounts for $70 \%$ of tremors, like other Indian study 13/15 (86\%) [2], whereas there was no case of ITS in the Australian study [3]. Psychogenic/behavioral causes (8\%) are relatively less common in India compared to others $23 \%$ [3]. To conclude, perinatal insult still is the most common cause indicating the need for improved perinatal care. Infantile tremor syndrome also formed a significant cause, emphasizing the need for improvement of nutritional status. Psychogenic causes and rheumatic chorea are less common.

\section{Declarations}

Conflict of Interest None.

\section{References}

1. Mink JW, Sanger TD. Movement disorders: an overview. In: Swaiman KF, Ashwal S, Ferrieri DM, et al, editors. Swaiman's Paediatric Neurology: Principles and Practice. 6th ed. Elsevier; 2018:706-16.

2. Goraya JS. Acute movement disorders in children: experience from a developing country. J Child Neurol. 2015;30:406-11.

3. Dale RC, Singh H, Troedson C, Pillai S, Gaikiwari S, Kozlowska K. A prospective study of acute movement disorders in children. Dev Med Child Neurol. 2010;52:739-48.

Publisher's Note Springer Nature remains neutral with regard to jurisdictional claims in published maps and institutional affiliations.
Vykuntaraju K. Gowda

drknvraju08@gmail.com

1 Department of Pediatric Medicine, Indira Gandhi Institute of Child Health, Bangalore, Karnataka, India

2 Department of Pediatric Neurology, Indira Gandhi Institute of Child Health, Bangalore, Karnataka, India 